\title{
Effective Treatment of Cutaneous Leishmaniasis with Photodynamic Therapy of Methylene Blue: A Case Report
}

\author{
K Kandri Rody*, S Amal and 0 Hocar \\ Department of Dermatology, Mohammed VI University Hospital, Cadi Ayyad University, Faculty of Medicine and Pharmacy - \\ Marrakesh, Morocco
}

*Corresponding author: K Kandri Rody, Department of Dermatology, Mohammed VI University Hospital, Cadi Ayyad University, Faculty of Medicine and Pharmacy - Marrakesh, Morocco

\section{ARTICLE INFO}

Received: 幽 February 28, 2020

Published: March 09, 2020

Citation: KKandri R,S Amal, OHocar. Effective Treatment of Cutaneous Leishmaniasis with Photodynamic Therapy of Methylene Blue: A Case Report. Biomed J Sci \& Tech Res 26(3)2020. BJSTR. MS.ID.004351.

\section{ABSTRACT}

Introduction: Photodynamic therapy is a currently used to treat neoplastic, inflammatory and infectious skin diseases. The purpose of this study was to show the efficiency of photodynamic therapy (PDT) using methylene blue (MB) to treat cutaneous leishmaniasis (CL).

Case presentation: We report the case of a 65-year old woman with CL consisting of one skin lesions that first developed 4 years earlier. The patient couldn't tolerate meglumine antimoniate so photodynamic therapy was used and resulted in satisfying results without relapse over 8 months.

Conclusion: Favorable clinical outcomes in our case suggest the utility of photodynamic therapy using Methylene Blue as treatment alternative for CL.

Keywords: Cutaneous leishmaniasis; Photodynamic therapy; Methylene Blue

Abbreviations: MB: Methylene Blue; CL: Cutaneous Leishmaniasis; PDT: Photodynamic Therapy; HIV: Human Immunodeficiency Virus; ALA: Aminolevulinic Acid; MAL: MethylAminolevulinic Acid

\section{Introduction}

Photodynamic therapy is a noninvasive treatment currently used to treat neoplastic, inflammatory and infectious skin diseases [1]. We report the case of a patient presenting cutaneous leishmaniasis who was effectively treated with photodynamic therapy, a therapeutic technique recently introduced in morocco.

\section{Case Presentation}

We report the case of a 65-year-old woman, skin type 3 and without particular history. She lives in tinghir, a cutaneous leishmaniasis endemic rural area in Morocco for Leishmania Major. She presented for four years a gradually enlarging skin lesion. On first presentation, the skin lesion measured $12 \mathrm{~cm} \mathrm{x} 9 \mathrm{~cm}$. It was non painful, vegetant and inflammatory with granular floor, and was located on the left dorsal foot (Figure 1). No palpable lymph nodes or splenomegaly were found. The patient had a stable weight and appeared to be in good general condition. Full blood count and biochemical tests were normal. Enzyme immunoassay for antibodies to human immunodeficiency virus (HIV) types 1 and 2 was negative. Dermal smears of the lesions were positive for cutaneous leishmaniasis. The patient was initially treated with intramuscular meglumine antimoniate. She presented on the 13th day following the injections intense abdominal pain, nausea and vomiting. Blood tests showed that serum lipase level was elevated to more than 6 times the upper limit of normal. The patient was intolerant to meglumine antimoniate and needed another treatment alternative. PTD was suggested.

After an intralesional injection of the MB solution (1\%), it was irradiated with red light for 15 minutes from a Waldman PDT 
$1200 \mathrm{~L}$ lamp at a light dose of $75 \mathrm{~J} / \mathrm{cm}^{2}$, a $82 \mathrm{~mW} / \mathrm{cm}^{2}$ of power and an emission wavelength of $680 \mathrm{~nm}(105 \mathrm{~J} / \mathrm{cm})$ (Figure 2). A total of four weekly treatments were performed. The side effect that was observed during the treatment is the pain caused by local skin photosensitization. In the protocol described here the patient reported moderate pain in the illumination area (pain scale: 6 out of 10). Treatment-associated pain was controlled by level 1 analgesic drugs and did not prevent treatment. Upon the follow-up visit eight months after the initial treatment, clinical improvement was obtained with the regression of $85 \%$ of the skin lesion that was cleared, leaving a faintly pigmentated scar on the treated site (Figure 3). Control dermal smears were negative for leishmania and the results were satisfying.

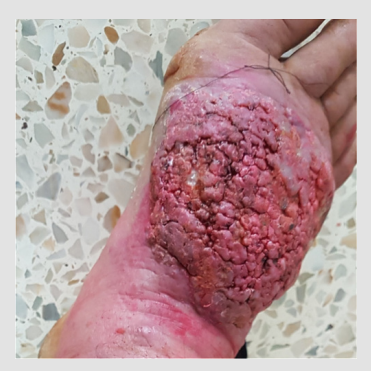

Figure 1:

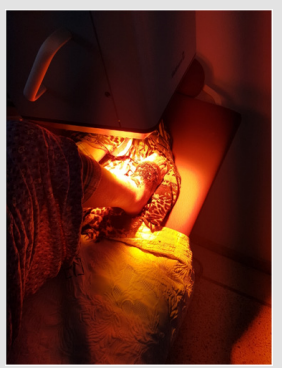

Figure 2:

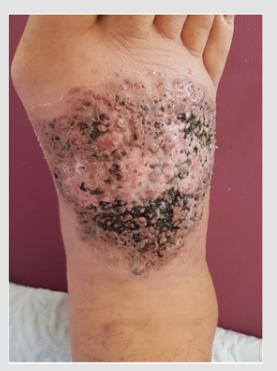

Figure 2:

\section{Discussion}

Cutaneous leishmaniasis is an emerging uncontrolled and neglected infection affecting millions yearly. It is a vector-borne disease caused by obligate, intracellular protozoa of the genus
Leishmania and transmitted by phlebotomine sandflies. It is a public health problem on a global level [2]. In Morocco, it is widely distributed, and new cases' numbers are increasing yearly [3]. Leishmania species can vary in their sensitivity to available therapeutic options [4], which makes of CL a therapeutic challenge [5]. Several treatment options are available. Pentavalent antimonial, such as meglumine antimoniate, are the first-choice treatment for CL. Alternative treatment regimens include antifungal agents (ketoconazole, fluconazole, itraconazol), and thermotherapy, cryotherapy or CO2 laser [6-8]. Our patient couldn't tolerate meglumine antimoniate. Therefore, PDT was indicated, which could be effective on the Leishmania major. PDT is based on the damage caused in biological tissues or in infecting microorganisms by light induced reactions, called photosensitization reactions [1]. Souza et al. believe that therapeutic mechanism of PDT in CL is the activation of the systemic immune response through neutrophils and cytokines (interleukins, TNF- $\alpha$ and interferon- $\gamma$ ) [9].

The most commonly used porphyrin precursors are aminolevulinic acid (ALA) or methyl-aminolevulinic acid (MAL) applied topically to skin lesions [4]. In our case, MB has been used as a low-cost photosensitizer of PDT and results were satisfying making of PDT with MB an effective in treatment of CL. The few reports that are available in the literature have validated this hypothesis $[4,7,10,11]$. The side effects that may be observed are mainly local as itch, burning sensations, erythema, oedema, hyperpigmentation and pain [12,13]. In our case, Treatmentassociated pain was controlled by level 1 analgesic drugs. Unlike systemic treatment, no systemic adverse effects from PDT were reported.

\section{Conclusion}

Results in our case show that the low-cost PDT protocol using MB source has the potential to be useful in the treatment of CL and can be a practical solution for treating this disease in underserved areas. Further studies are needed to test the efficiency of this protocol in a statistically significant population of patients.

\section{Author Disclosure Statement}

No conflicting interests exist.

\section{References}

1. Elloudi S, Baybay H, Meziane M, Chakiri R, Gallouj S, et al. (2016) Photothérapie dynamique: Expérience du service de dermatologie du CHU Hassan II de Fès. In Annales de Dermatologie et de Vénéréologie 143(12): p. S404.

2. Elbenaye J, Miloudi M (2015) Leishmaniose cutanée érysipéloide: A propos d'une observation clinique. Pan African Medical Journal 21(1): 54.

3. Rhajaoui M, Nasereddin A, Fellah H, Azmi K, Amarir F, et al. (2007) New Clinic-epidemiologic profile of cutaneous leishmaniasis Morocco. Emerg Infect Dis 13(9): 1358-1360.

4. Heras Mosteiro J, Monge Maillo B, Pinart M, Pereira PL, Garcia Carrasco E, et al. (2017) Interventions for Old World cutaneous leishmaniasis. Cochrane Database of Systematic Reviews 11: CD005067. 
5. Johansen MB, Jemec GBE, Fabricius S (2019) Effective treatment with photodynamic therapy of cutaneous leishmaniasis: A case report Dermatologic Therapy 32: e13022.

6. Solomona M, Traua H, Schwartz E (2008) Old-world cutaneous leishmaniasis: An ancient disease in wait of new drugs. Ann Dermatol Venereol 135(5): 357-359.

7. Gardlo K, Horska Z, Enk CD, Rauch L, Megahed M, et al. (2003) Treatment of cutaneous leishmaniasis by photodynamic therapy. Journal of the American Academy of Dermatology 48(6): 893-896.

8. Taslimi Y, Zahedifard F, Rafati S (2018) Leishmaniasis and various immunotherapeutic approaches. Parasitology 145(4): 497-507.

9. Souza DM, Alves PM, Silva MLF, Paulino TP, Coraspe HO, et al. (2017) 5-ALA-mediated photodynamic therapy reduces the parasite load in mice infected with Leishmania braziliensis. Parasite Immunology 39(3): e12403.

ISSN: 2574-1241

DOI: $10.26717 /$ BJSTR.2020.26.004351

K Kandri Rody. Biomed J Sci \& Tech Res

(C) This work is licensed under Creative

Submission Link: https://biomedres.us/submit-manuscript.php
10. Song D, Lindoso JAL, Oyafuso LK, Kanashiro EHY, Cardoso JL, et al. (2011) Photodynamic therapy using methylene blue to treat cutaneous leishmaniasis. Photomedicine and laser surgery 29(10): 711-715.

11. Fink C, Toberer F, Enk A, Gholam P (2016) Effective treatment of cutaneous leishmaniasis caused by Leishmania tropica with topical photodynamic therapy. JDDG: Journal Der Deutschen Dermatologischen Gesellschaft 14(8): 836-838.

12. Nassif PW, DE MELLO TFP, Navasconi TR, Mota CA, Demarchi IG, et al. (2017) Safety and efficacy of current alternatives in the topical treatment of cutaneous leishmaniasis: A systematic review. Parasitology 144(8): 995-1004.

13. Miller IM, Nielsen JS, Lophaven S, Jemec GBE (2011) Factors related to pain during routine photodynamic therapy: A descriptive study of 301 patients. Journal of the European Academy of Dermatology and Venereology 25(11): 1275-1281.

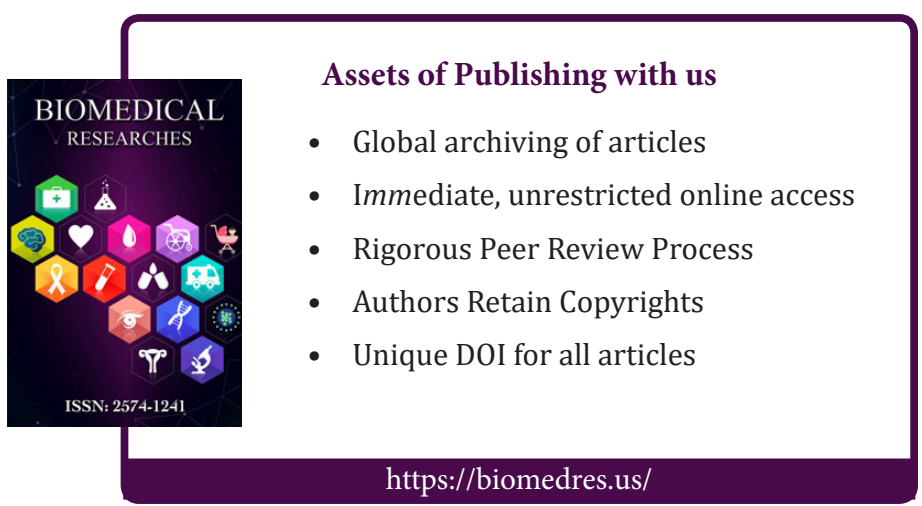

